\title{
KALIBRASI PARAMETER HIDROGRAF SATUAN SINTETIK NAKAYASU (STUDI SUNGAI-SUNGAI DI SULAWESI SELATAN )
}

\author{
MUHAMAD YAMIN ${ }^{1)}$,BAGUS WIDHI DHARMA $S^{2)}$ \\ Fakultas Teknik UNMAS Denpasar PSDKU Mataram \\ e-mail: ${ }^{1)}$ sumberdayaair8@gmail.com. ${ }^{2)}$ Bagus.widhi.dharma@gmail.com
}

\begin{abstract}
ABSTRAK
Banyak hidrograf satuan sintetik telah dikembangkan antara lain Hidriograf Satuan Sintetik Nakayasu berdasarkan pengamatan empiris di Jepang. Meskipun penentuan parameter telah disajikan dengan berbagai kriteria, namun sejauh ini hasilnya masih relative menyimpang jika diterapkan untuk DAS-DAS di Indonesia, sehingga perlu dilakukan kalibrasi terhadap beberapa parameter yang dipakai.

Penelitian ini merupakan penelitian kajian yang dilakukan pada 3 sub DAS di Propinsi Sulawesi Selatan dengan menggunakan type menyebar yaitu sub DAS Maros,Sub DAS Tallo dan sub DAS Jeneberang. Parameter yang akan dikalibrasi ada 2 yaitu koefisien $\alpha$ dan Ctg dengan tg $=0,04-0,0058 \mathrm{~L}$, kalibrasi yang dilakukan didapat harga $\alpha$ dan Ctgyang sesuai untuk masing-masing DAS.

Hasil kajian menunjukkan bahwa pemakaian metode Nakayasu untuk keperluan analisis hidrograf banjir yang merupakan alih ragam dari data hujan di Indonesia, perlu dilakukan modifikasi, terutama terhadap parameter-parameter yang dipakai. Untuk mendapatkan kisaran parameter berdasar parameter karakteristik DAS, perlu dilakukan kajian lanjutan pada banyak DAS berdasarkan tipe DAS.
\end{abstract}

Kata kunci : Kalibrasi parameter hidrograf, satuan sintetik Nakayasu

\section{ABSTRACT}

Many synthetic unit hydrographs have been developed including the Nakayasu Synthetic Hydriograph based on empirical observations in Japan. Although the determination of parameters has been presented with various criteria, so far the results are still relatively distorted if applied to watersheds in Indonesia, so it is necessary to calibrate some of the parameters used.

This research is a research study conducted in 3 sub-watersheds in South Sulawesi Province by using a type of spread, namely the Maros sub-watershed, Tallo sub-watersheds and Jeneberang sub-watersheds. There are 2 parameters to be calibrated, namely the coefficient $\alpha$ and Ctg with $t g=0.04-0.0058 \mathrm{~L}$, the calibration done is obtained $\alpha$ and Ctg values corresponding to each watershed.

The results of the study indicate that the use of the Nakayasu method for the purposes of the analysis of flood hydrographs which is a change in the variety of rainfall data in Indonesia, needs to be modified, especially to the parameters used. To get a range of parameters based on the parameters of watershed characteristics, it is necessary to conduct further studies on many watersheds based on the type of watershed.

Keywords: Hydrograph parameter calibration, Nakayasu synthetic unit 


\section{PENDAHULUAN}

\section{Latar Belakang}

Penentuan banjir rancangan memberikan hasil yang bermanfaat bila disajikan dalam bentuk hidrograf banjir. Informasi yang dapat diberikan dari hasil pengalihragaman hujan menjadi hidrograf limpasanakan lebih banyak. Sejauh ini penurunan hidrograf satuan dari hidrograf banjir teramati merupakan salah satu cara yang dianggap relative akurat. Namun kendala utama yang dihadapi adalah sulitnya mendapatkan data hidrograf banjir pengamatan, sehingga berkembanglah penurunan hidrograf yang didasarkan pada sintetis parameter bentuk aliran sungai, dan dikenal dengan hidrograf sintetik.

Banyak hidrograf satuan sintetik yang telah dikembangkan, anrata lain Hidrograf Satuan Sintetik Nakayasu sesuai berdasarkan pengamatan empiris di Jepang.Meskipun dalam penentuan parameterparameternya telah disajikan dengan berbagai kriteria, namun sejauh ini hasilnya msih relative menyimpang jika diterapkan untuk DAS-DAS di Indonesia, sehingga dalam pemakainnya perlu dilakukan kalibrasi terhadap beberpara parameter yang dipakai.

Menurut Cordery (1991 : 153), jika data observasi (hidrograf pengamatan) salah (terjadi error, seperti pengamatan data hujan rerata daerah,dll) dan jika teori hidrograf satuan relative tidak mencerminkan karakteristik DAS yang bersangkutan, maka hidrograf satuan yang didapat berdasar persamaan di atas tidak dianggap mewakili DAS yang bersangkutan. Jhonstone and Cross (1949) dalam Cordery (1987) mengemukkan teori lain, yang dikenal dengan metode Collins (Collins Method). Hidrograf satuan pengamatan dapat diturunkan dari data hujan terpisah dengan intensitas merata atau hujan periode tunggal, yaitu rangkaian kejadian curah hujan yang hanya menghasilkan satu curah hujan efektif dalam setiap satuan waktu.Hal tersebut jarang dijumpai, sedangkan yang banyak dijumpai adalah hujan periode kompleks, ayitu curah hujan efektif yang dihasilkan lebih dari satu.

\section{Rumusan Masalah}

Berapakah nilai parameter-parameter hidrograf satuan sintetik Nakayasu yang sesuai untuk diterapkan pada DAS Maros, Tallo dan Jeneberang?

\section{Tujuan dan Manfaat}

Tujuan penelitian ini yaitu untuk menyajikan nilai parameter-parameter hidrograf satuan sintetik Nakayasu yang sesuai untuk diterapkan pada DAS Maros, Tallo dan Jeneberang. Sedangkan manfaat penelitian diharapkan bisa memberikan sumbangan berharga dalam perencanaan bangunan keairan karena perencanaan banguan keairan sangat penting untuk mengetahui besaran banjir rancangan dan hidrografnya

\section{LANDASAN TEORI}

Metode Collins merupakan salah satu cara untuk mendapatkan hidrograf satuan pengamatan dengan data hujan periode kompleks.

Prosedur pengamatan Metode Collins :

1. Menentukan hidrograf limpasan langsung pengamatan dengan memisahkan aliran dasar dari hidrograf pengamatan

2. Menentukan volume limpasan langsung yang diakibatkan oleh hujan $1 \mathrm{~mm}=$ luas DAS $* 1 \mathrm{~mm}$ hujan

3. Menentuak lebar dasar hidrograf $t b=k=n-j+1$, dengan $k, n$ dan $j$ seperti ditakrirkan diatas

4. Menentukan ordinat hidrograf satua awal (coba-coba-1) = volume limpasan langsung (butir 2) dibagi dengan tb (butir 3)

5. Menentukan hidrograf limpasan langsung yang diakibatkan oleh hujan efektif di DAS yang bersangkutan, kecuali untuk harga hujan efektif terbesar ( $R_{\text {eff }}$ maks). Jumlah limpasan langsung $=\sum R U$

6. Mencari selisih antara ordinat hidrograf limpasan langsung (butir $5=R U$ ) dengan hidrograf pengamatan $(=Q)$, jumlahnya $=\sum(Q-R U)$

7. Mencari $U_{t}-1$ pada masing-masing ordinat $=(Q-R U) / R_{\text {eff }}$ maks jumlahnya $\sum\left[(Q-R U) / R_{e f f}\right.$ maks $]$

8. Mencari faktor perubahan = luas DAS/3600 dibagi dengan $\sum\left[(Q-R U) / R_{e f f}\right.$ maks $]$

$\rightarrow$ ketemu $U_{t}-1$ jus ( $=U t-1$ yang telah diperbaiki)

9. Menghitung faktor $F=\sum(Q-R U) / \sum R U$ 
10. Mengalihkan $U t-1$ jus dengan $F \rightarrow$ ketemu $F^{*} U t$ jus

11. $U t-1^{*}=\left[\left(F^{*} u t\right.\right.$ jus $\left.)+U t-1\right] /(1+F)$, jumlahnya $=\sum U t-1^{*}$

12. $U t-2=U t-1 *$ dikalikan dengan (luas DAS/3600) $\sum U t-1 *$

13. Jika volume Ut awal belum sama dengan volume $U t-2$, maka coba-coba ini dilakukan sampai mendapatkan hasil yang relative sama (toleransi 4\%)

\section{Hidrograf Satuan Sintetik Nakayasu}

Menganalisa hidrograf banjir rancangan berdasarkan Metode Hidrograf Satuan Sintetik Nakayasu, perlu diketahui karakteristik daerah alirannya yang dirupakan dalam parameter-parameter. Paramater yanhg dimaksud adalah:

1. Tenggang waktu dari permulaan hujan sampai puncak hidrograf (time to peak magnitude)

2. Tengganhg waktu dari titik berat hujan sampai titik berat hidrograf (time lag)

3. Tenggang waktu hidrograf (time base of hydrograph)

4. Luas daerah pengaliran (Catchment area)

5. Panjang alur sungai utama terpanjang (leght of the longest channel)

6. Koefisien pengaliran (runoff coefficient)

Rumus Hidrograf Sintetik Nakayasu adalah sebagai berikuit, (Soemarto,1987) :

$Q p=\frac{C \cdot A \cdot R o}{3,6(0,3 \cdot T p+T \cdot 0,3)}$

dimana:

$Q p=$ debit puncak $\left(\mathrm{m}^{3} / \mathrm{det}\right)$

$R o=$ hujan satuan $(\mathrm{mm})$

$T p=$ tenggang waktu dari permukaan hujan sampai puncak banjir (jam)

T0,3 = waktu yang diperlukan oleh penurunan debit, dari debit puncak sampai menjadi $30 \%$ dari debit puncak (jam)

Untuk menentukan Tp dan $\mathrm{T} 0,3$ digunakan rumus :

$T p=\operatorname{tg}+0,8 \mathrm{tr}$

$T 0,3=\alpha \cdot \operatorname{tg}$

dimana:

$T g$ = waktu antara hujan samapi debit puncak banjir (time lag) (jam)

$T g$ dihitung berdasar atas :

Jika panjang sungai $>15 \mathrm{Km}$ :

$\mathrm{Tg}=0,40+0,058 . \mathrm{L}$

Jika panjang sungai $<15 \mathrm{Km}$ :

$T g=0,21 . \mathrm{L}$

$\alpha=$ parameter hidrograf

$\operatorname{Tr}=$ satuan waktu hujan ( 1 jam)

Persamaan hidrograf satuannya adalah:

1. Pada waktu naik:

$0 \leq \mathrm{t}<\mathrm{tp}$ :

$Q t=\operatorname{Qmaks}\left(\frac{t}{t p}\right)^{2,4}$

2. Pada kurva turun :

$0 \leq \mathrm{t}<(\mathrm{tp}+\mathrm{t} 0,3):$

$\frac{t-t p}{t 0,3}$

$\mathrm{Qt}=$ Qmaks * 0,3

$(\mathrm{tp}+\mathrm{t} 0,3) \leq \mathrm{t}<(\mathrm{tp}+\mathrm{t} 0,3+\mathrm{t} 0,3):$

$\frac{t-t p+t 0,3}{1,5 \cdot t 0,3}$

$\mathrm{Qt}=\mathrm{Q}$ maks * 0,3

$\mathrm{T} \geq(\mathrm{tp}+\mathrm{t} 0,3+1,5 \mathrm{t} 0,3):$

$\frac{t-t p+t 0,3}{1,5 \cdot t 0,3}$

$\mathrm{Qt}=\mathrm{Q}$ maks * 0,3 
Rumus tersebut di atas merupakan rumus empiris,sehingga sebelum menerapkan rumus tersebut, pada suatu daerah aliran sungai perlu dilakukan kalibrasi parameter yang sesuai seperti tg, $\alpha$ dan pola distribusi hujan, agar didapatkan suatu pola hidrograf yang sesuai dengan hidrograf banjir pengamatan.

\section{METODE PENELITIAN}

Penelitian ini merupakan penelitian kepustakaan (rebrary research). Langkah awal yang dilakukan dalam penelitian ini adalah mengumpulkan data, baik data lapangan maupun historis yang menunjang kajian tersebut. Data yang dikumpulkan berupa:

1. Hidrograf pengamatan di satuan AWLR (Automatic Water Level Recorder) pada masing-masing DAS yang diamati

2. Data hujan otomatis sesuai dengan pengamatan AWLR

3. Data karakteristik DAS

\section{HASIL DAN PEMBAHASAN}

Hidrograf satuan diperoleh berdasarkan hasil pengamatan menguunakan cara Collins, sebagai pertimbangan pemilihan hidrograf satuan dan hitungan Collins tersebut dialihragamkan lagi menjadi debit berdasar kejadian hujan yang telah diolah (hujan efektif). Karena kalibrasi parameter yang dilakukan berupa menyesuaikan waktu banjir dan debit puncak banjir, maka hidrograf pengamatan yang mewakili juga dilaksanakan pada simpangan terkecil antara hidrograf limpasan hitungan Collins dan hidrograf limpasan langsung pengamatan.

Parameter yang dikalibrasi dalam kajian ini adalah koefisien karakteristik DAS ( $\alpha$ dan Ctg), yang merupakan pangkat L dalam persamaan tg/waktu konsentrasi). Untuk mendapatkan hidrograf satuan sintetik Nakayasu hasil kalibrasi yang mempunyai simpanan terkecil waktu puncak dan debit puncaknya terhadap hidrograf satuan Metode Collins yang mewakili, maka mula-mula dilakukan kalibrasi terhadap satu parameter dulu. Dasar kalibrasi adalah mencari simpangan yang relative kecil (dengan kesalahan 0,001) terhadap debit puncak dan waktu puncak (waktu tiba banjir).

Persamaan baku parameter tg dalam Metode Nakayasu :

a. Untuk L $<15 \mathrm{~km}$ : $\operatorname{tg}=0,21$. L

b. Untuk L > $15 \mathrm{~km}: \operatorname{tg}=0,4+0,058$. L

Untuk keperluan kalibrasi (Ctg), rumus ini diubah menjadi :

a. Untuk $\mathrm{L}<15 \mathrm{~km}$ : $\operatorname{tg}=0,21$. L

b. Untuk $\mathrm{L}>15 \mathrm{~km}$ : $\operatorname{tg}=0,4+0,058$. L

Kalibrasi ini akan dilakukan dengan 2 indikasi yaitu :

a. Melalui hidrograf sintetik

b. Melalui hidrograf limpasan langsung

Hasil kalibrasi untuk masing-masing sungai DAS disajikan sebagai berikut:

Gambar 1. Hidrograf Satuan DAS Maros

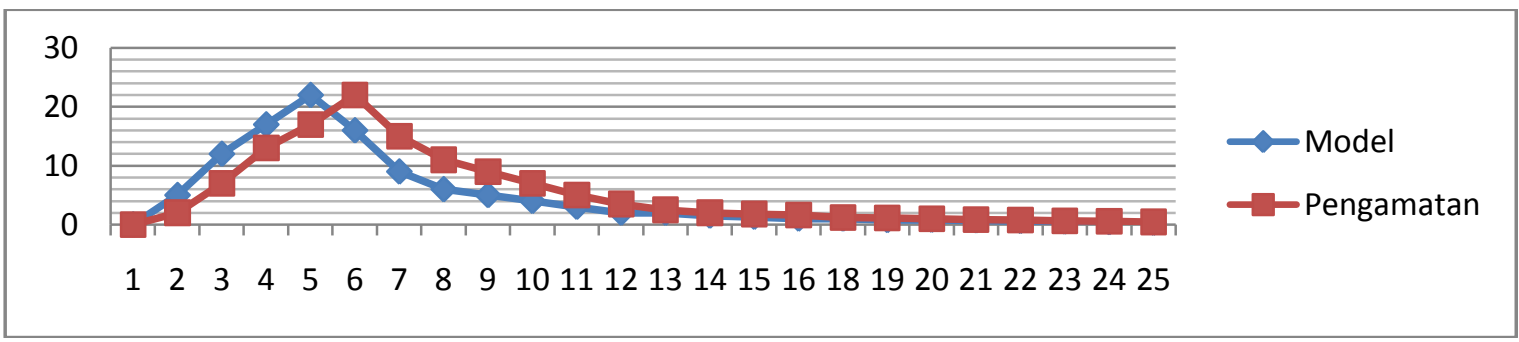


Gambar 2. Hidrograf Satuan Limpasan Langsung DAS Maros

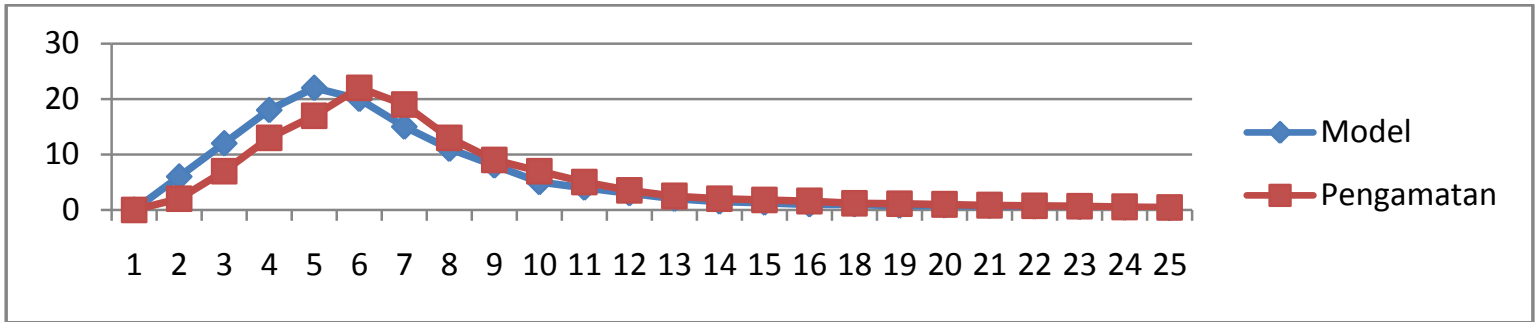

Gambar 3. Hidrograf Satuan DAS Tallo

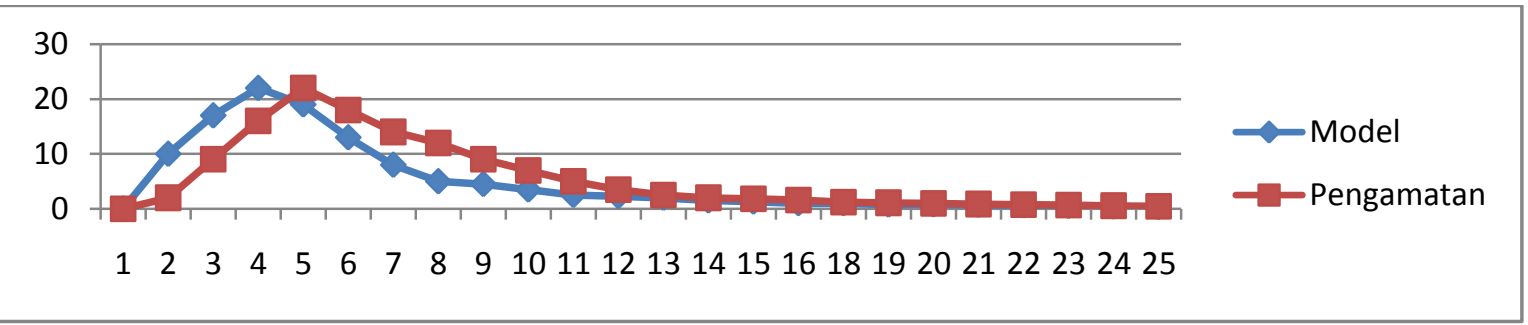

Gambar 4. Hidrograf Satuan Limpasan Langsung DAS Tallo

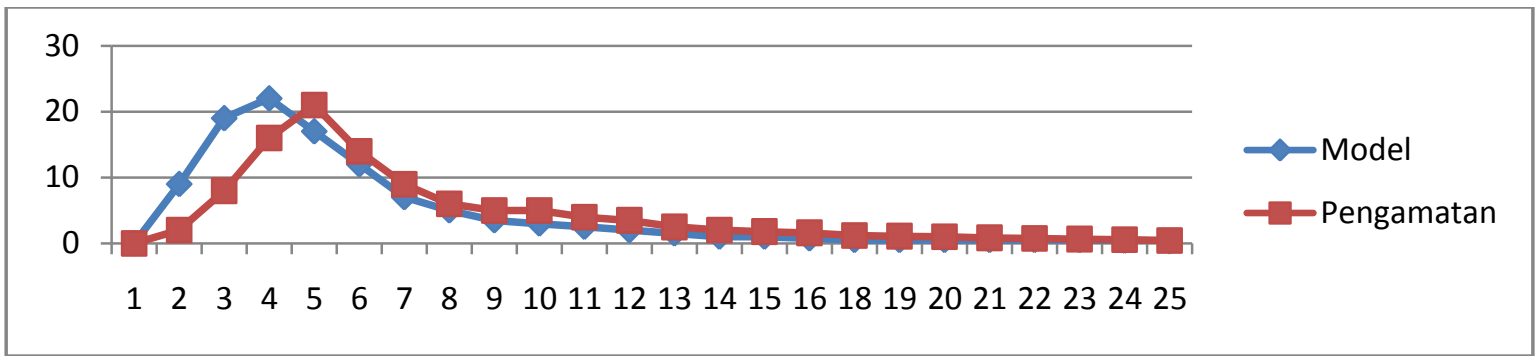

Gambar 5. Hidrograf Satuan DAS Jeneberang

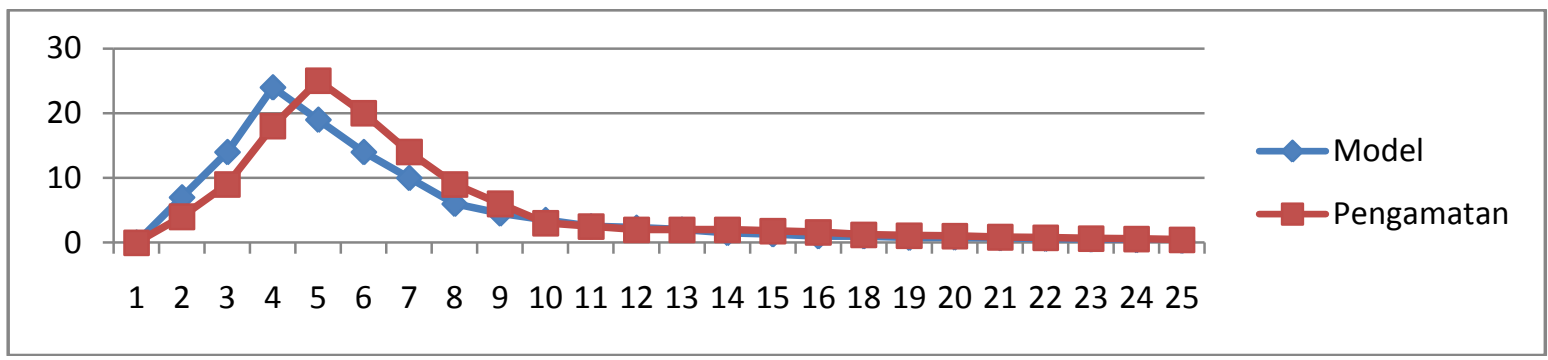

Gambar 6. Hidrograf Satuan Limpasan Langsung DAS Jeneberang

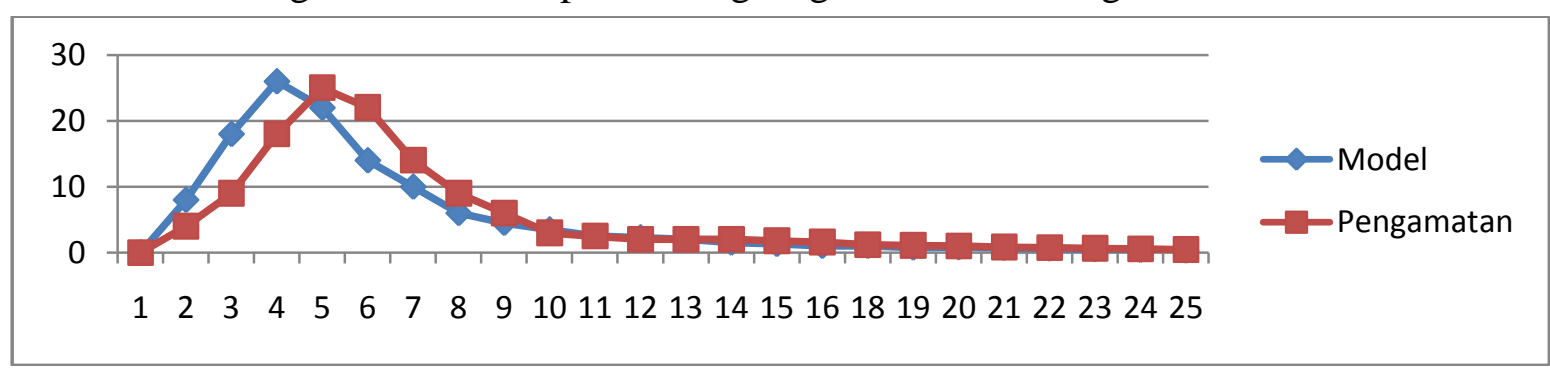




\section{PENUTUP}

\section{Simpulan}

Berdasarkan kajian yang telah dilakukan pada 3 DAS yaitu Maros, Tallo dan Jeneberang mengenai kalibrasi parameter $\alpha$ dan Ctg pada Hidrograf Satuan Sintetik dan Hidrograf Limpasan Langsung Metode Nakayasu, maka dapat disimpulkan sebagai berikut:

1. Kalibrasi parameter hidrograf satuan

\begin{tabular}{|l|c|c|c|c|c|}
\hline \multicolumn{1}{|c|}{ DAS } & $\mathrm{A}(\mathrm{km})$ & $\mathrm{L}(\mathrm{km})$ & $\alpha$ & $\mathrm{Ctg}$ & $\operatorname{tg}$ \\
\hline Maros & 601 & 65 & 0,8569 & 1,2310 & \\
Tallo & 309 & 61 & 0,9351 & 0,9451 & $0,4+0,058 . \mathrm{L}$ \\
Jeneberang & 757 & 80 & 1.2033 & 1,1435 & \\
\hline
\end{tabular}

2. Kalibrasi parameter hidrograf satuan

\begin{tabular}{|l|c|c|c|c|c|}
\hline \multicolumn{1}{|c|}{ DAS } & $\mathrm{A}(\mathrm{km})$ & $\mathrm{L}(\mathrm{km})$ & $\alpha$ & $\mathrm{Ctg}$ & $\operatorname{tg}$ \\
\hline Maros & 601 & 65 & 1,1241 & 1,2310 & \\
Tallo & 309 & 61 & 1,2567 & 0,9451 & $0,4+0,058 . \mathrm{L}$ \\
Jeneberang & 757 & 80 & 1.2033 & 1,1435 & \\
\hline
\end{tabular}

3. Kalibrasi parameter hidrograf satuan dan hidrograf limpasan langsung memberikan hasil parameter $\alpha$ dan Ctgyang relatif berbeda. Hal ini diduga karena:

a. Proses alihragam limpasan langsung menjadi hidrograf satuan hitungan Collins masih mengalami error. Mengingat metode Collins merupakan salah satu cara coba-coba sehingga hasilnya tidak tepat sama dengan hidrograf satua yang sebenarnya.

b. Adanya ordinat relatif berbeda antara hidrograf satuan hitungan metode Collins dengan hidrograf satuan sebenarnya akan membawa adanya rambatan kesalahan pada proses alih ragamhujan menjadi limpasan langsung yang berpedoman pada hidrograf satuan hitungan Collins.

4. Kedua hal diatas diduga sebagai penyebab terjadinya perbedaan hasil kalibrasi parameter pada hidrograf satuan dan hidrograf limpasan langsung.

5. Berdasarkan kalibtrasi yang telah dilakukan maka untuk DAS yang semuanya berbentuk menyebar. Untuk menghasil suatu model parameter untuk DAS-DAS dikawasan tertentu, perlu dikaji lagi untuk DAS-DAS yang berbentuk bulu burung dan sejajar,termasuk pengkajian ulang untuk ke 3 DAS yang berbentuk menyebar, denga data DAS yang relatif banyak.

\section{Saran-saran}

Penentuan banjir rancangan memberikan hasil yang bermanfaat bila disajikan dalam bentuk hidrograf banjir dan penentuan parameter-parameter untuk DAS-DAS di Indonesia dalam pemakainnya perlu dilakukan kalibrasi terhadap beberpara parameter yang dipakai.

\section{DAFTAR PUSTAKA}

Hoan Charles,T. 1977.Statisyika Method In Hydrology. The Lowa State University Press

Harto,Sri,Bar. 1983.Mengenal Dasar-Dasar Hidrologi Terapan. Biro Penerbit keluarga MahasiswaTeknik Sipil UGM. Yogyakarta

-------. 1988. Mode Hydrology. PAU Ilmu Teknik UGM. Yogyakarta

Linsley Ray,K,Max.A Kohler,and Joseph LH,Danlus. (1986). Hydrology For Engineer (Alih Bahasa Yandi Hermawan). Jakarta

Pattison,A.,FIE,AUST,JKG Word,Mc Mohan and B. Watson. 1977.Australia Rainfall Runoff Analysis and Design.Australia: The Institutions of Engineer Australia.

Pilgrem,DH. (1987). Australa Ranfall and Runoff. Australia: The Instutitions of Engineer Australia. Soemarto CD. (1897). Hidrologi Teknik. Surabaya: Usaha Nasional Surabaya.

Viesman,Wariien,Kanpp,Jhon W., Lewis Bary.L., and Harbough Terencu.E. 1972.. Introduction to Hydrology.London: Hasper and Raw Publisher London. 